\title{
INFLUENZA AS A PROBLEM OF HOSPITAL ADMINISTRATION
}

\author{
K. R. D. PorTer, M.R.C.S., L.R.C.P., L.D.S., R.C.S., D.P.H. \\ Deputy Senior Administrative Medical Officer, Birmingham Regional Hospital Board
}

My task this morning is to discuss with you the administrative problems of influenza. These are not inconsiderable and become more difficult in a city such as Birmingham which is served by hospitals administered by three separate hospital management committees, together with the Teaching Hospital Group under the Board of Governors.

What, then, is the problem and is it a purely quantitative one? What are the steps that can be taken to deal with it ? I want in the course of this paper to set the problem of the onset of influenza against the background of a number of factors which have made the problem progressively more difficult to deal with.

Table I shows the number of requests for admission to the Bed Bureau from January 1955 to February 1963. From this table a number of facts emerge:-

(a) The annual totals have increased by nearly $20 \%$.

(b) The major load, as one would normally expect, comes in January and February and there is an increase from January 1955 to January 1963 of $32 \%$.

(c) Comparing the January and July figures for 1955 and 1962 respectively, it will be seen that the July figure for 1955 is $62 \%$ of January 1955 , and the July figure for 1962 is $67.6 \%$ of January 1962 . From this two major facts emerge:

(i) The winter load of 1955 has become the summer load of today; and

(ii) The difference between the summer and the winter loads is becoming less as the years go by.

It might be thought that, because the Bed.
Bureau is an easy way for the general practitioners to admit patients to hospital, the general practitioners, in general, are using the Bed Bureau more frequently with less direct approach to the hospital of their choice as has been the practice for many years past. In fact, this is not so. There has been no diminution in the number of cases admitted direct to hospital.

Looking at Table I, except in 1959 the major load has occurred during January and, in fact, has come a week or ten days after Christmas when the hospitals were filling up after being relatively empty over the Christmas holiday.

Tables 2, 3, 4, 5 and 6 are graphs showing the weekly rate of admissions through the Bed Bureau for the winter months $195^{8-59}$ to $1962-63$. It will be noticed that the graphs also show the weekly number of persons drawing sickness absence benefit and for the years $196 \mathrm{I}-62$ to $1962-63$ the number of respiratory cases requiring admission to hospital. Also shown are periods when a sharp increase in bronchiolitis in children has occurred for which, unfortunately, no exact statistical information has been kept. What undoubtedly is evident from these charts is that the onset of bronchiolitis in children heralds an increase in chest infections in adults approximately three weeks later. One would immediately then pose three questions:-

(a) Can the occurrence of bronchiolitis in children in significant numbers be a warning device to alert hos-

TABLE $x$

Birmingham Bed Bureau-Monthly Total Calls, I955-ig63

\begin{tabular}{|c|c|c|c|c|c|c|c|c|c|c|c|c|c|c|}
\hline Year & & Jan. & Feb. & March & April & $\begin{array}{c}\text { May } \\
\text { May }\end{array}$ & June & July & Aug. & Sept. & Oct. & Nov. & Dec. & $\begin{array}{c}\text { Annual } \\
\text { Total }\end{array}$ \\
\hline 1955 & $\ldots$ & 1,385 & I, I 49 & 1,333 & 1,122 & 1,036 & 988 & 860 & 886 & 903 & 1,023 & I , I 59 & I, 269 & 13,113 \\
\hline 1956 & $\cdots$ & $1,35^{2}$ & 1,182 & I, 197 & 1,028 & 1,063 & I,006 & 912 & 793 & 858 & 1,066 & 1,023 & 1,061 & 12,541 \\
\hline I 957 & $\ldots$ & I, I I 5 & 1,082 & 1,168 & 1,034 & 1,043 & $95^{\circ}$ & 920 & 871 & 1,128 & 1,355 & 1,091 & 1,326 & I 3,083 \\
\hline 1958 & $\ldots$ & $I, 480$ & 1,252 & 1,324 & 1,073 & 946 & 984 & 954 & 848 & 882 & I, 039 & 1,057 & 1,2 I 5 & I 3,054 \\
\hline 1959 & $\ldots$ & 1,619 & 1,969 & 1,293 & 1,177 & $\mathbf{I}, 02 \mathrm{I}$ & 1,064 & 1,064 & 1,038 & 1,040 & I, OI 5 & 1,136 & 1,064 & 14,500 \\
\hline 1960 & .. & 1,260 & 1,318 & 1,371 & 1,264 & 1,161 & 1,118 & I, I I 9 & 1,042 & 1,028 & 1,200 & 1,249 & 1,646 & I 4,776 \\
\hline I96I & .. & I,875 & 1,327 & 1,301 & 1,294 & 1,299 & 1,284 & I, I4I & I, I 10 & 1,124 & 1,195 & I,208 & 1,527 & I 5,685 \\
\hline $\begin{array}{l}1962 \\
1963\end{array}$ & $\cdots$ & $\begin{array}{l}1,646 \\
1,814\end{array}$ & $\begin{array}{c}1,176 \\
(1,690)\end{array}$ & $I, 45^{I}$ & 1,345 & 1,288 & 1,182 & I, I I 3 & 1,096 & 1,162 & 1,226 & 1,223 & $1,5 \circ 5$ & 15,413 \\
\hline
\end{tabular}

Figures for February 1963 provisional only. 


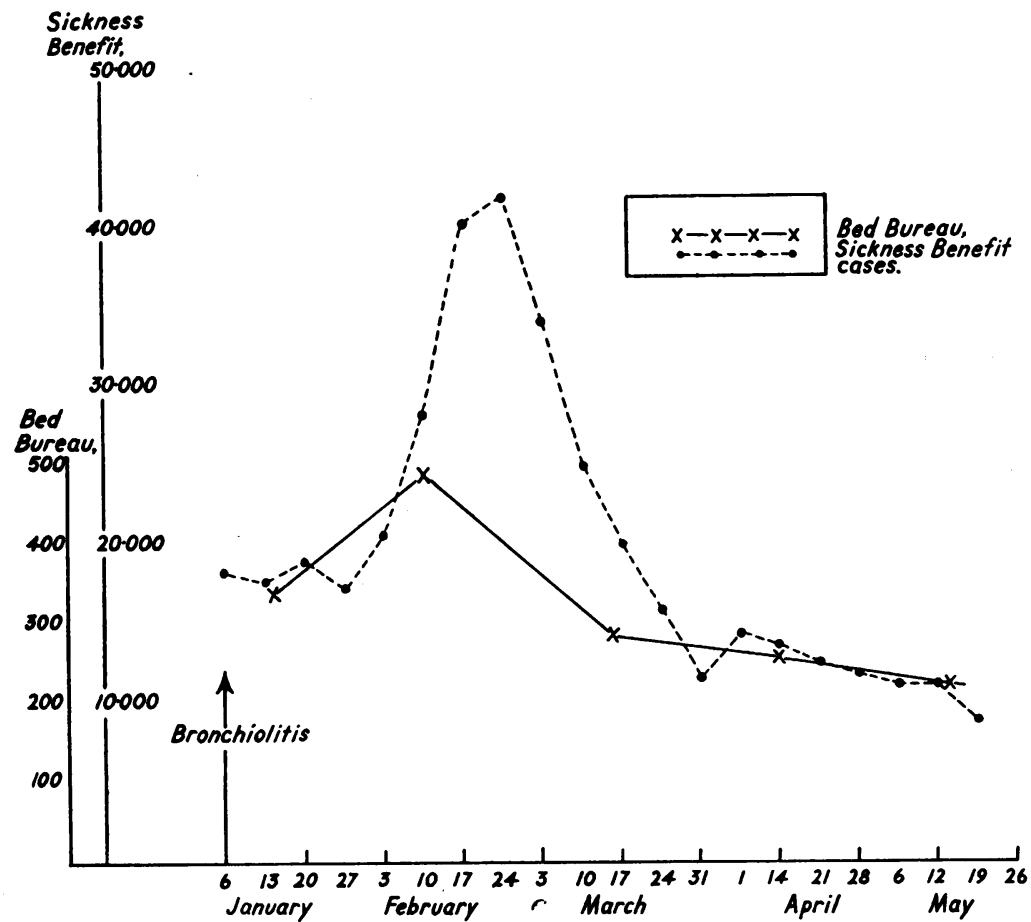

TABLE 2.-Weekly claims to sicknessbenefit, Birmingham region $\vec{x}$ and weekly rate of admissionso through the Bed Bureau, 1959응

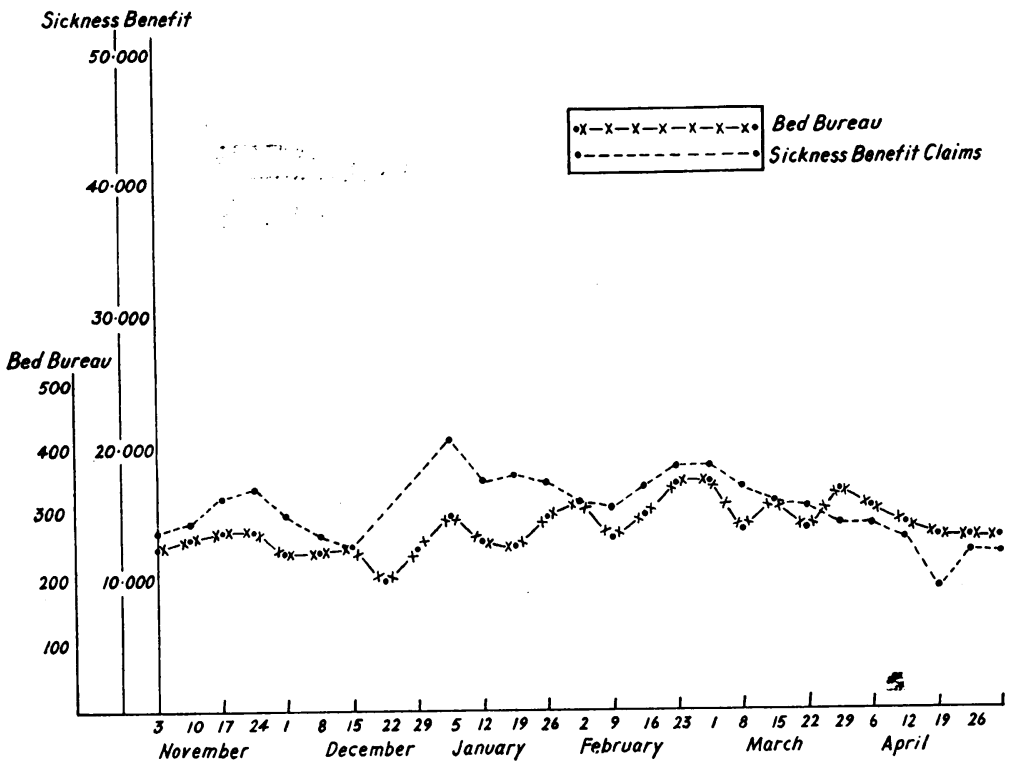

TABLE 3.-Weekly claims to sicknessbenefit, Birmingham region 30 and weekly rate of admissions through the Bed Bureau, I 959-60.

pitals that they may expect, within three weeks, a large number of adults with acute respiratory infections requiring admission?

(b) Is the organism responsible for bronchiolitis in children likely to be responsible, or at least partly responsible, for the adult infections?

(c) Are there any preventive measures that can be carried out, either by general practitioners or the locat health authority, to reduce the risk of winter infectionsD in the elderly? Should the introduction of zones of clean air be hastened and extended? Is there anyo form of reservoir of infection in the home that should be investigated and eradicated? These are importan questions to which attention must be given if any? resolution of the problem is to be found. 


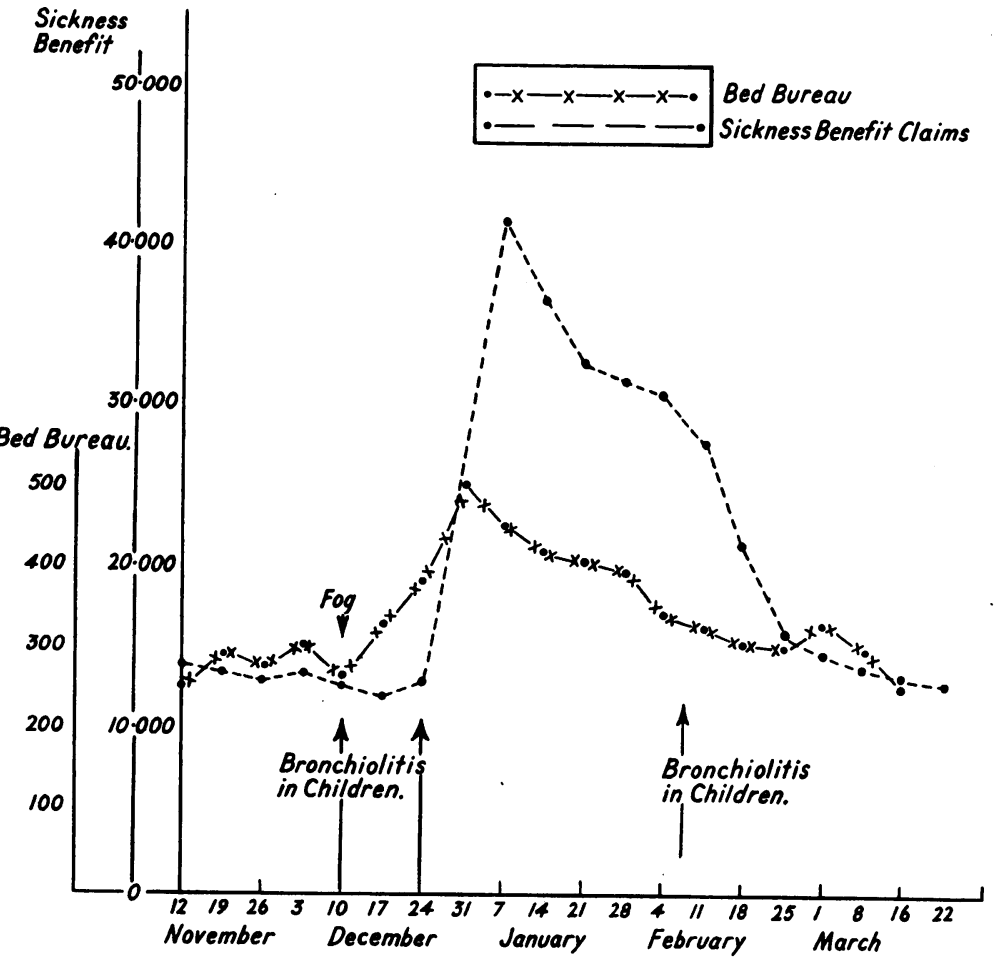

TABLE 4.-Weekly claims to sickness benefit, Birmingham region, and weekly rate of admissions through the Bed Bureau, r960-6r.

Chest Cases

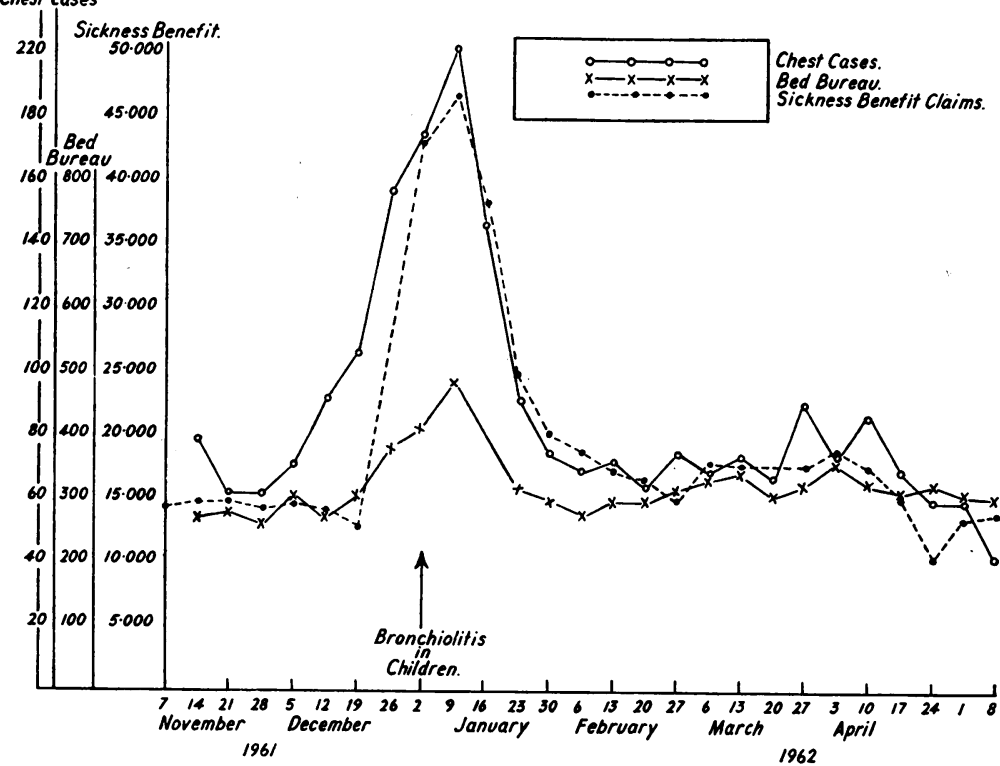

TABLE 5.-Weekly claims to sickness benefit, Birmingham region, and weekly rate of admissions through the Bed Bureau, 1961-62. 
Sickness Benefits

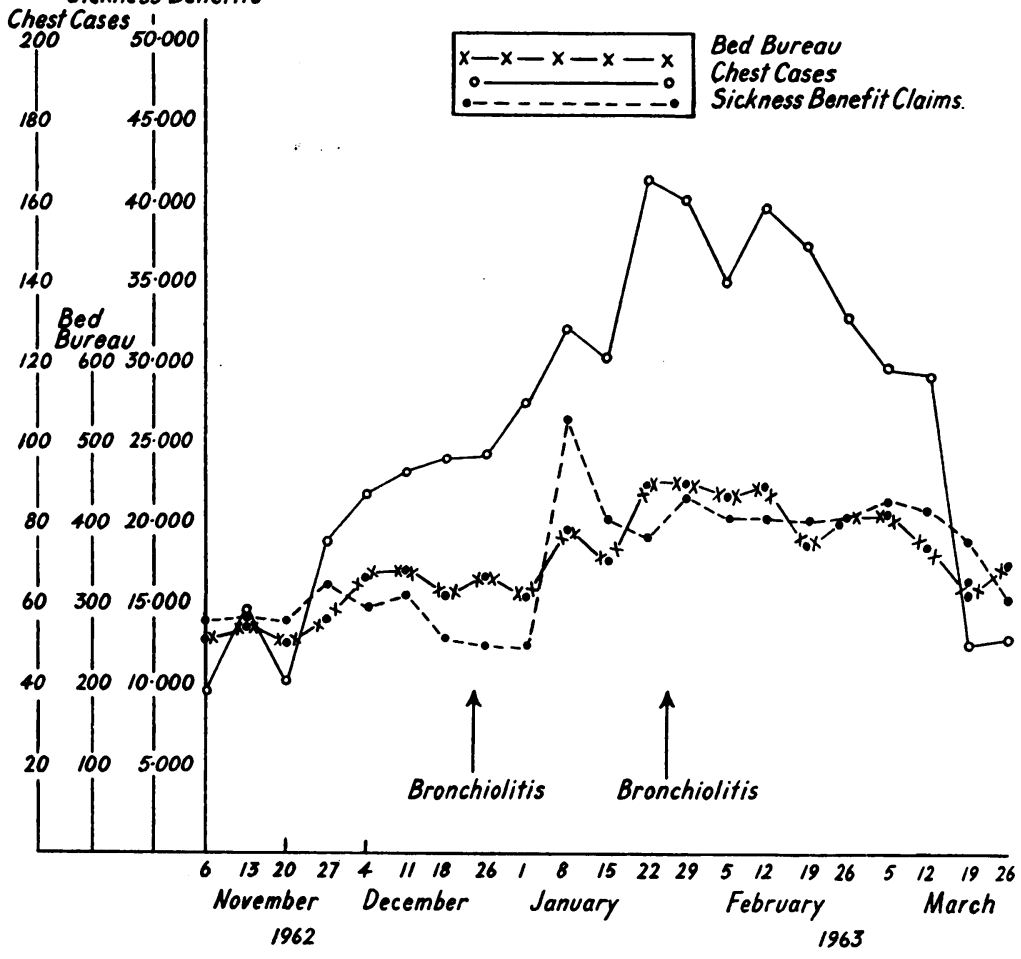

TABLE 6.-Weekly claims to sickness $\vec{\omega}$ benefit, Birmingham region, and weekly rate of admis-? sions through the Bed Bureau, $1962-63$.

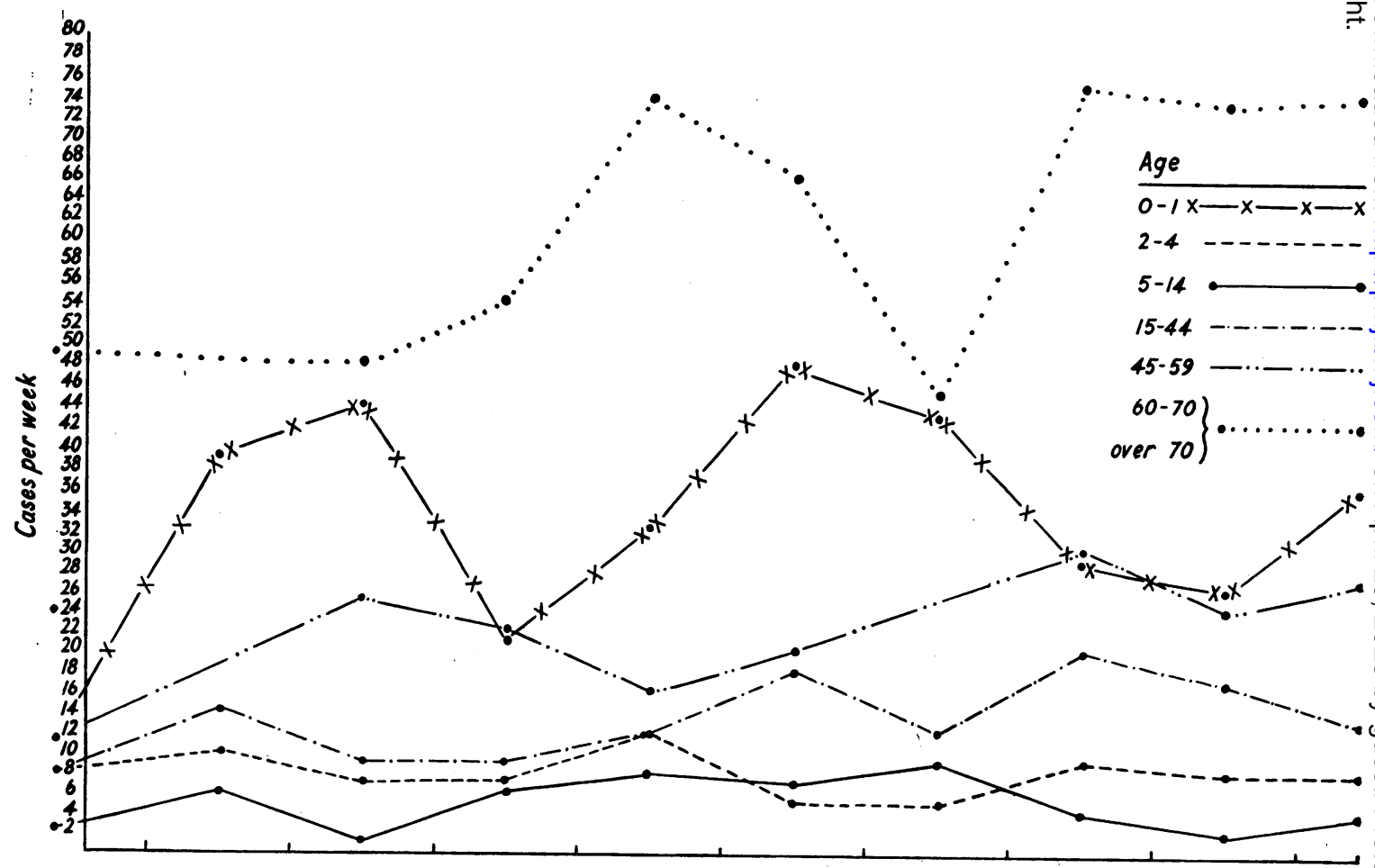

TABLE 7.-Bed Bureau respiratory emergencies-ten weeks period, December 22, 1962, to March I, 1963. 
The winter of $1962-63$ has been almost unique Although following the typical pattern up until Christmas, a sharp increase in respiratory cases occurred after Christmas, although few A type virus infections occurred. The peak, which usually is passed in a matter of a week or ten days, this year remained, however, for a period of four weeks.

An analysis by age groups and broad diagnostic headings of cases admitted through the Bed Bureau for the ten-week period December 22, 1962, to March I, 1963, shows that the respiratory group forms between a third and just under a half of the total admissions. It also shows that children under the age of $I$ and persons over the age of 60 provide anything up to three-quarters of the total of cases admitted as respiratory emergencies. The respiratory emergencies from each of the ten weeks' period have been extracted and are shown graphically in Table 7 . The relationship of the peaks for children under $I$ and the over-6os is striking and underlines the point that was made earlier that the onset of bronchiolitis in children heralds an increase in the respiratory infections in the over-6os.

Superficially it would seem that, in spite of better housing, better diet, more leisure and improved standards of living, the country, if Birmingham is a fair sample, is becoming more sickly and more patients require admission to hospital as emergencies. On closer examination, however, this is not really likely to be the case and a number of explanations might be worth giving:-

(a) Patients who are chronic bronchitics and who have an acute exacerbation in the winter months now recover. Previously they died. They now recover to live to be readmitted later. In parenthesis the Midlands, with their coal mining and foundry work, produce rather more persons with damaged lungs than average and these are the ones particularly at risk.

(b) There might well be a change in the social pattern of death in that fewer people are being allowed to die at home. This, in turn, might be due to the fact that, with husband and wife working they cannot look after the elderly patient and, secondly, that in a vigorous city to which young people are drawn for employment the elderly are left with none to care for them.

(c) With improved standards of living are people any less prepared to look after the ill than they were seven years ago ? Is, in fact, admission to hospital too easy? This is unlikely to be wholly true, for those admitted today as emergencies are every bit as ill as those in the past.

With the large number of elderly people being admitted to hospital they naturally take a longer period to recover with the result that there is a silting up of the acute medical wards. The chronic sick beds are, in their turn, filled and they, in their turn, cannot transfer patients to welfare accommondation because of the lack of places that can be provided by the welfare authorities.

There are three further points that need highlighting:-

(a) With the increased load of medical emergencies there is, as a rule, during the winter months either a slowing down or a complete cessation of admissions of cold cases from the surgical waiting list. This has but one result, namely that of increasing the size of the surgical waiting list. It might be argued that with the coming of the summer months when the load of medical cases has decreased, the surgeons could catch up, but this is not always possible because:-

(i) There is not sufficient theatre time.

(ii) There are not enough anæsthetists or surgeons to take advantage of any possible increase in theatre time that may be available.

(iii) In any case the emergency load in the summer time has already been shown to have increased.

(b) To meet the increased load of emergencies during the winter months it is estimated that an additional 400 beds are required. For Birmingham City alone their provision would represent a very large capital expenditure.

(c) If there has been an increase in load of $20 \%$ from 1955 to 1962 is this increase likelyo to continue at the same rate and is there ever? likely to be a halting of this process ? Is the country heading towards a silting up of acute beds by the repeated readmission of elderly patients with respiratory infections ?

Against the background of the rising rate of requests for emergency admissions, the onset of a genuine influenza epidemic such as was experienced in February 1959, poses a strain on hospital resources which is almost unbearable. Extra beds are of no great value, for the nursing and medical staffs are not immune and the employment of part-time staff invariably suffers. The pooling of all available staff, be they Local Authority or Hospital, would seem the only way of meeting a crisis such as this.

Having highlighted a number of factors, how, then, is the problem to be solved ? The Board set up a committee under the chairmanship of one of the consultants, consisting of clinicians and administrators from all three Management Committees and from the Teaching Hospital to see how best the resources available can be used to the maximum advantage. This committee meets approximately once every six weeks and more frequently if necessary and recommends to the Board the steps that are to be taken to meet this increased load. The help that ${ }^{\circ}$ this committee and particularly its chairman has given has been 
outstanding and the co-operation of the hospitals administered by the Board of Governors has been unstinting. Amongst its many recommendations has been the introduction of a coloured warning system which, in essence, is a method by which hospitals and general practitioners and indeed, the general public, can be alerted and warned that the load is becoming increasingly difficult to bear. It also, as a final step, indicates when it feels that the situation has got so serious as to merit a complete ban, (except for urgent cases such as carcinoma,) on the admission of patients from the waiting list. This means, in fact, that gynæcological beds and surgical beds are placed at the disposal of the physicians.

It is also recognized that paradoxically the putting up of extra beds in a ward did not in fact increase the number of patients admitted. The putting up of extra beds led to the gross overworking of nursing staff and to outbreaks of cross infection and they in turn led to an increased duration of stay with fewer patients? put through each bed. The maintenance of minimum distance between heads and a limit. placed on the number of beds in each ward has been shown to shorten the average duration of stay and to increase the number of patients put through each bed.

The Committee also keeps a watch on the्ल various developments in Birmingham to ensure that the closure of departments as a result of thes developments will not interfere with the number 5 of beds available.

A lot of work, investigation and hard thinking has to be carried out to find means by which the increased load can be met or in what way the load can be lessened.

Finally, we know so little about the conditionse and environment in which the elderly live. Af series of surveys is long overdue to find ouf more exactly what happens to them and in whate way the welfare state fails to meet their needs?

\section{Discussion following the paper of Dr. Cross}

DR. RoDEN remarked that bed bureau statistics were sensitive indices of influenza in the community, and reflected pressure of work on general practitioners as well as on hospital beds.

Dr. HEARN said that in his unit during the last winter all febrile admissions had been screened against viruses by the complement fixation method, in the same way as the cases investigated during the epidemic he had described yesterday. The results showed that no particular virus disease was prevalent and assumed that we were dealing, during this last wintor with a different factor. Very few high titres against viruses were found as compared with the last two winters.

DR. Cross wondered whether hospital admissions were particularly high because of the low temperatures and whether the excessively low temperatures caused the amount of influenza to be low. 